\title{
HIV/AIDS Prevention and Care Strategies: An Interdisciplinary Perspective
}

\section{Fyson Hanania Kasenga*}

Department of Health and Medical Informatics, Malamulo College of Health Sciences Campus, Sweden

\begin{abstract}
An extensive literature review on HIVIAIDS Prevention and Care Strategies was done from February to June, 2003 at Diakonhjemmet College, International Department in Oslo, Norway. Information from both developed and developing countries was examined. The main source of information included HIVIAIDS publications and text books extracted from the already existing resources. Furthermore, the author's experience from Malawian context acted as a catalyst throughout the entire write up of this document.

The exercise aimed at documenting HIVIAIDS management strategies on various levels of intervention developments. It sought to unveil possible obstacles experienced by aid agencies in HIVIAIDS programs and the application of their policies/priorities to more diverse cultural settings. The paper seeks to address factors that are responsible for HIV transmission and how to deal with them in a more acceptable and an interdisciplinary manner. Consequently, examples of success stories that have emanated from effective HIVIAIDS management have been cited to influence the readers' intuition in fighting against HIVIAIDS.

It is estimated that 40 million of adults and children are living with HIVIAIDS worldwide. Many of these people are in developing countries. In sub-Saharan Africa, over 21 million people are living with AIDS. In 13 countries in the region at least $10 \%$ of all adults are HIV infected and the prevalence rates in many capital cities are $35 \%$ or more. Hospitals cannot cope up with admissions of HIVIAIDS related conditions. It is estimated that by 1998, 800,000 people in Malawi had already died of AIDS since the epidemic started. Many of them were adults in their most productive years (15-45). This is very unfortunate because the young adults are the ones upon whom the development of the country depends.

Currently, $16 \%$ of the Malawian population is living with HIVIAIDS. It is therefore necessary to utilize every effort that will help to reduce HIV transmission and improve the quality of life for those who are already infected. It is in the light of this that the document seeks to provide added possibilities to those who are committed and dedicated in alleviating human suffering worldwide.
\end{abstract}

Keywords: AIDS; Obstacles; HIV transmission

\section{Abbreviations/Acronyms}

AIDS-Acquired Immunodeficiency Syndrome

CDC-Centre for Disease Control and Prevention

CHAM-Christian Hospitals Association of Malawi

ELISA-Enzyme-Linked Immuno-sorbent Assay

FHI-Family Health International

FP-Family Planning

HIV-Human Immunodeficiency Virus

HTLV-T-lymphocytrophic Virus 3

IDU-Injection Drug User

LAV-Lymphocytic Associated Virus

MCH-Maternal and Child Health

MSF-Medecins Sans Frontieres

NGO-Non-Governmental Organization

OIs-Opportunistic infections

PMCT-Prevention of Mother to Child Transmission of HIV

PLWA-Persons Living with HIV/AIDS

PSI-Population service International

STIs-Sexually Transmitted Infections
Tb-Tuberculosis

UNDP-United nations Development Programme

UNAIDS-Joint United Nations Programme on HIV/AIDS

UNICEF-United Nations Children Fund

VCT-Voluntary Counseling and Testing

WFP-World Food Programme

WHO-World Health Organization.

\section{Introduction}

Human immuno-deficiency virus (HIV) is an infectious agent that causes AIDS. Luc Montagnier of Pasteur Institute in Paris called it lymphocyte-associated virus (LAV) when he discovered it in 1983. Independently, US scientist Robert Gallo of the National Cancer Institute in Bethesda, Maryland claimed its discovery in 1984 and named it T-lymphocytotrophic virus 3 (HTLV-3).

${ }^{*}$ Corresponding author: Fyson Hanania Kasenga, PhD, MPH, Department of Health and Medical Informatics, Malamulo College of Health Sciences Campus, Sweden, Tel: +265 (0) 888366 419; E-mail: fkasenga@sdnp.org.mw

Received October 18, 2017; Accepted November 07, 2017; Published November 10, 2017

Citation: Kasenga FH (2017) HIVIAIDS Prevention and Care Strategies: An Interdisciplinary Perspective. J Health Med Informat 8: 291. doi: 10.4172/21577420.1000291

Copyright: $\odot 2017$ Kasenga FH. This is an open-access article distributed under the terms of the Creative Commons Attribution License, which permits unrestricted use, distribution, and reproduction in any medium, provided the original author and source are credited. 
Worldwide, heterosexual activity accounts for three-quarters of all HIV infections and about 40 million people have already been infected with the virus [1]. In addition to heterosexual men and women, high risk groups are homosexual and bisexual men, prostitutes, intravenous drug users sharing needles, and hemophiliacs and other patients treated with contaminated blood products. The virus has short life outside the body, which makes transmission of the infection by methods other than sexual contact, blood transfusion and shared syringes extremely unlikely.

In sub-Saharan Africa, over 21 million people are living with HIV/ AIDS. In 13 countries in the region at least $10 \%$ of all adults are HIV infected and the prevalence rates in many capital cities are $35 \%$ or more. For instance Botswana and Zimbabwe have reached a prevalence of $30 \%$, or one out of every four adults in the country is infected [2].

Malawi with an estimated population of 11.5 million has not been spared from AIDS epidemic. It has the prevalence rate of $16 \%$ among adults and it is increasing daily [3]. Malawi Government recognizes HIV/AIDS as a serious public health and socio-economic problem requiring multisectoral involvement. Many hospital admissions are due to HIV/AIDS related conditions. Furthermore, $70 \%$ of hospital deaths in Malawi are due to AIDS. Other public health problems too require attention of the same health facilities. This poses pressure on the health facilities whose resources are inadequate.

US researchers in 1995 developed an explanation of why HIV is transmitted mainly by heterosexual sex in Africa and Asia and by homosexual sex and intravenous drug use in Europe and the USA. They found that HIV variant subtype B-responsible for $90 \%$ of European and US cases did not grow well in reproductive tract cells, whereas subtype B-common in developing countries did grow well. If subtype E becomes more prevalent in Europe and the USA, infection patterns will probably change. The first case of subtype $\mathrm{E}$ in Britain was documented in May $1996[4]$.

However, there are many factors that facilitate the HIV transmission. Among these factors are poverty, cultural beliefs and gender inequalities which are later explained in this paper. Many HIV infected people are not ill. Initially it was thought that during the delay between infection with HIV and the development of AIDS the virus lay dormant. However, US researchers estimated in 1995 that HIV reproduces at a rate of a billion viruses a day even in individuals with no symptoms, but is held at bay by immune system producing enough white blood cells (CD4 cells) to destroy them.

Gradually the virus mutates so much that immune system is unable to continue to counteract, people with advanced AIDS have virtually no CD4 cells remaining. These results indicate the importance of treating HIV positive individuals before symptoms develop, rather than delaying treatment until the onset of AIDS.

About $15 \%$ of babies born to HIV positive mothers are themselves positive. A very small number of these babies (less than 3\%) test negative for the virus some months later, a phenomenon yet to be explained. HIV test is done by using Enzyme-linked Immunosorbent Assay (ELISA) and Agglutination. This test is highly sensitive, specific and identifies specimen with reactive antibodies. However, specimen must be shown to be repeatedly reactive before they are considered positive in the initial test.

AIDS patients like any other patients need care and support to meet their basic needs. The difference is that AIDS being a chronic disease needs continuous care and support based on love. Communication skills and compassion are essential to providing good care for the sick.

\section{Statement of the problem}

As reported in the background, AIDS is one of the leading causes of death in the world. In Africa, south of Sahara desert, it is extremely life threatening. Hospitals cannot cope up with admissions of HIV/ AIDS related conditions. It is estimated that by $1998,800,000$ people in Malawi had already died of HIV/AIDS since the onset of the epidemic [5]. Many of them were adults in their prime years (15-45). This is very unfortunate because the young adults are the ones upon whom the development of the country depends. Furthermore, the number of orphans is increasing. It is becoming difficult for families to keep them.

Inadequate health services, poverty and culture have largely contributed to the wide spread of HIV infection in sub-Saharan Africa and other developing countries. Clinical services offering sexually transmitted infections (STIs) care are an important access for people at high risk for both HIV and STIs. Therefore, control and prevention of STIs have been recognized as a major strategy in prevention of HIV and ultimately AIDS [6]. Effective strategies and well defined donor policies will not only improve HIV/AIDS patients' lives, but will also facilitate the change of behavior, understanding and acceptance of HIV/AIDS.

\section{Justification}

It has been a tradition for families to look after their sick and the orphans. Before the advent of AIDS, it was difficult to recognize orphans in the communities. The system enabled the children of the deceased to be cared for by the relatives. Currently, this is not possible because the number of orphans world-wide has largely increased. This is worse in sub-Saharan countries. For instance, Malawi's estimated number of orphans is 470,000 and this figure is unstable as many people continue to lose their lives to AIDS [7].

These orphans suffer from different problems such as diseases, malnutrition, child labour, sexual abuse and of course the list is endless. There is needed to closely look into the package of HIV/AIDS preventive and care strategies in order to effectively reduce its transmission. Donors need to streamline and scale up their ways of funding to suit the disadvantaged communities. Communities need to be empowered to air out their felt needs regardless of their situation. The paper strives at providing additional knowledge to Diakonhjemmet and any other people who may have an opportunity to read it. Furthermore, this is applicable to all civil societies dealing with HIV/AIDS interventions. In a nut shell, this is the basis of this piece of work.

\section{Objectives}

Overall objective: To document HIV/AIDS management strategies on various levels of intervention developments.

Specific objectives: 1 . To identify possible ways of reducing HIV transmission in people at risk from different cultural settings.

2. To compile findings on the impact of effective HIV/AIDS prevention and care.

3. To determine policies and priorities on HIV/AIDS among different relevant donors.

\section{Prevention Strategies}

AIDS management is a controversial issue worldwide. This is partly because the disease has no cure. The use of the antiretroviral drugs is very helpful in reducing human suffering and improving the quality of life. This is achieved by slowing down the progression of the disease. However, the holistic approach should be adhered to when dealing 
with persons living with HIV/AIDS (PLWA). Fear and prejudice are significant obstacles to the translation of technical knowledge into appropriate treatment.

However, HIV/AIDS is linked with so many sensitive and volatile issues such as sexuality, death, drug use and in other places race and class. An individual wishing to take up the responsibility of caring for the AIDS patients in a true sense must be ready to meet with such challenges. To provide such care, members of the health team and the community need to work together and indeed they need just more than technical information.

The appropriate strategies for HIV/AIDS management should be adopted. These include; actual care, material and logistic support, health education on behavioral change and treating them as equals. Basically the care should aim at prolonging their lives. Furthermore, the care for AIDS patients does not end even after they have died. This is because they leave a number of dependents most of whom are children who still need tender parental care. It is as a result of this that communities are overwhelmed by an increased number of orphans.

HIV passes from person to person through different routes. Different preventive strategies have been developed to slow down the spread of AIDS along each of these routes. The most common strategies are listed below; grouped into categories according to the route of transmission they normally address.

\section{Sexual transmission (Biological interventions)}

Sexually transmitted infections (STIs) prevention and control: Effective treatment of sexually transmitted infections has been observed significantly to reduce HIV transmission. Therefore, treatment of both partners and follow up of the cases should be intensified. To achieve this, procurement of STI drugs in many health facilities should be maintained.

Change in sexual behaviour is very important in preventing the spread of HIV. Sexually transmitted infection projects should aim at promotion of safe sexual behaviour through information, education and communication (IEC). Furthermore, they should promote condom use, STI care seeking behaviour and provision of effective STI care. The STI clients should be followed up including their sexual partners.

The majority of STI clients fail to visit health facilities for treatment due to health workers' attitude and lack of privacy among other factors. The barriers need to be minimized and made friendly for all the people as well as the youth. Community sensitization should be made to ensure consistent service utilization by many clients as in certain areas STI services are free.

Knowledge regarding HIV/AIDS among the youth is relatively high. Therefore, it is important to design interventions that are targeted at behaviour change. Young people have different perceptions regarding AIDS prevention. A study that was done in Nigeria showed high (94\%) knowledge, awareness and perception of STIs among adolescent female High School students [8]. Perhaps this is an area worth looking at as many college students engage in unprotected sexual intercourse. Furthermore, the outbreak of AIDS among the young people is already present at the moment.

Vaccines and microbicides: Recent advances in coming up with HIV vaccine has so far proved a failure. The later appears to be one of the promising biological interventions, although it is not widely used by many clients. It is hoped that in future these will be in circulation.
A preventive vaccine is our best hope for ending the global AIDS pandemic. A microbicide (a protective gel, foam or cream) against HIV infection would give individuals especially women around the world greater ability to protect themselves from HIV infection [9]. A vaccine and microbicide could save tens of millions of lives, yet both these products face a variety of challenges that require expanded research efforts in both the public and private sectors.

\section{Behavioral interventions}

Formal HIV/AIDS and health education: Education of the public about HIV/AIDS so far appears to be the key means of intervention of AIDS. For education to bring change in human behaviour it must be well designed. It will therefore be able to reach and affect the intended audience, and fit the changing environment. Effective designing of AIDS message intervention, periodic assessment of the current knowledge and attitude of the people is important. The significance of this approach is to enable people living with HIV/AIDS afford care that will suit their environment without risking cross infection.

Frequently medical education about AIDS like medical education in general relies on cognitive model with the implicit assumption that an increase in knowledge and skills will lead to improved care. Support to the assumption is especially important in AIDS since anxiety and stigmatization play such a large part in a social response to the disease [10].

Introduction of school sexual education and sexuality has been seen as breakthrough in many societies. Teachers and all significant others should be trained in this aspect of activity and should also be encouraged to be living examples. Education in this aspect should be aimed at relatively permanent change of behaviour.

Enthusiasm for promoting behaviour change as a direct route to our prevention, is dampened by a large body of research that demonstrate that socio-economic and cultural factors considerably influence risk of HIV infection [10]. In the case of resource poor environments, such factors can dramatically limit personal empowerment to make safer sex choices. These factors include poverty, limited access to health and social services, labour migration, urbanization, unemployment, poor education, the inferior social position of women, diversities in language and culture, amongst others.

Mass media campaigns: Media can be a powerful means of disseminating HIV/AIDS information to large groups of people. Consideration should be made when using certain means to reach people. This is because in rural areas access to audio visual aids is very limited. The majority of people depend on radios most of the times. It is also important to use the language or languages that are commonly understood by the indigenous people. Holding meetings with the chiefs and their respective communities has been proved effective in many communities in Africa [11].

In many situations it has been observed too difficult to find out exactly what should be contained in the messages addressed to people. However, knowledge, emotions and the targeted behaviour should always be put in mind. The crust of the matter is that the three dimensions mentioned above should be affected by whatever messages we wish to put across.

Mass media is one of the powerful strategies in HIV/AIDS prevention. Results from the study done by a Centre for Disease Control and Prevention [11], revealed that comprehensive sexuality education is effective in reducing teen age sexual activity and increasing safer sex among teens who do have sex. 
Social marketing of condoms: Condoms should be made accessible to those who need to use them. The ideal thing would be to encourage people to abstain from casual sexual relationships and to stick to one faithful sexual partner. However, it has been observed that the majority of individuals engage in casual sex. Therefore, to ensure maximum protection of these people, it is advisable that they consistently make use of condoms.

It should also be mentioned that the use of condoms does not provide $100 \%$ protection from sexually transmitted infections including HIV/AIDS. People should be given enough information on how to effectively use the condoms and where to get them. People who practice high risk behaviours such as sex workers, homosexuals and long truck drivers among others should always have condoms at their disposal.

In Malawi (author's experience), there is a beer making company that has engaged in this activity and the outcome is very good. It has well trained members of staff who know pretty well how to reach these people. The interesting aspect of it is that its customers are those who are at risk and it is easy for this company to deal with them.

Social marketing programs have helped make condoms more accessible and affordable to various segments of the society, including low income and high risk groups in many developing countries. In 2000, 1.2 billion condoms were sold at below market prices through social marketing programs in 59 countries $[12,13]$.

Targeted interventions: It should be stressed that the presence of HIV/AIDS in the world today puts everybody at risk regardless of the background. However, some people may be at risk due to the circumstances that surround them. These include young people, women, commercial sexual workers, drug users and alcoholics. It is important that these people are dealt with respect and dignity since they are human beings like anybody else. Often, programs fail to achieve this because of the judgmental attitude.

People with risk behaviours are at high risk of HIV infection. Therefore, it is of vital importance to learn about these risk behaviours in order to design and implement effective HIV/AIDS programs [14], reported that despite the surveyed population's high level of HIV/ AIDS knowledge, their own risk perception of potentially becoming infected with the virus is very low in all groups. This means that action against HIV/AIDS must address the deadly gap between knowledge and behaviour.

Looking low upon people infected with HIV contradicts proper offering of care to them. This may partly affect the caregiver himself but largely the recipients, since doing good and feeling bad at the same time is not good enough. In the case of women and especially in the case of sex workers who have experienced social stigma, feelings of powerlessness and low self-worth are indeed a dilemma. Telling them how they should act is tantamount to blaming them for their predicament.

Injection drug use: HIV incidence continues to rise among injection drug users (IDUs). Injection drug use accounts for only 5 percent to 10 percent of cumulative HIV infection globally, but in some parts of the world, it is the major mode of HIV transmission [15]. A comprehensive strategy that promotes behaviour change through harm reduction is essential to HIV programming for IDUs.

HIV epidemics among IDUs are distinguished from those of other populations by their potential for rapid spread of the virus within the IDU community and outward into the general population.
Most of these infections result from sharing or reusing contaminated equipment (mainly needles and syringes) or from injecting tainted drug preparations.

Today many HIV/AIDS workers are experiencing pressures both internally and externally which lead to their loss of morale and burnout. Some of the HIV/AIDS workers who actually lived with AIDS have had episodes of exhaustion, sickness and death. On the other hand, people living with AIDS are coming up although the amount of work they put on tends to be of short-term. This is also applicable to injection drug users.

A unique feature of the groups of AIDS workers who, over years, succeeded in creating tight national and international networks is that the groups included persons living with HIV/AIDS. Provision of sterile drug equipment, outreach and peer education, access to health care and testing and treatment should be part and parcel of people working with the drug addicts.

Blood transfusion: The risk of being infected with HIV after blood transfusion is minimal since screening of blood donors and blood supply is the order of the day. It should further be emphasized that any health facility that deals with blood transfusion applies safety measures to reduce post transfusion HIV/AIDS.

Over the years laws and regulations were emphasized in respective duties of every blood transfusion related departments. The strictly controlled imported blood products, carefully blood screening on donor, standardized blood products, tightened control on indication of use of blood and careful told rare happened HIV/AIDS to recipients are the key measures to avoid forensic cases of post transfusion HIV/ AIDS [16].

Mother to child transmission: In Africa, quite a substantial number of HIV infected babies are born from HIV positive mothers. This is because a majority of them can hardly access to antiviral prophylaxis. It is of late (author's experience), that the Medecins Sans Frontieres (MSF) initiated the Prevention of Mother to Child Transmission (PMCT) in two of the districts in Southern Malawi called Thyolo and Chiradzulu. Pregnant women are given Nevirapine before delivery. I believe it is a good move in combating HIV infection among the innocent new borns.

Issues surrounding women's reproductive health and reproductive health care are extremely sensitive in some parts of the region, but the human rights message is clear. Every woman has the fundamental right to decide whether to have children, whether to find out their HIV status, and how best to feed their infants [17]. States have a duty to see that they are provided with relevant information and support with services in their respective local context.

All children, regardless of their own or their parents' HIV status, have the right to education, care in the family or in another appropriate family-like environment, best available health care, freedom from discrimination, protection from abuse and adequate standard of living. Perhaps, this is why provision of antiviral drug to pregnant mothers as a prophylaxis should be encouraged at all levels of HIV prevention in maternal and child health $(\mathrm{MCH})$ clinics.

In general, prevention of HIV infection in women, use of antiretroviral drugs before birth and provision of health alternatives to breast feeding should be emphasized at all times. However, due to the scarcity of resources women in Africa and other developing countries have very limited options. Majority of them continue breastfeeding in the presence of HIV infection. Failure to do this, children will ultimately die of malnutrition. 
Empowerment of women and young girls: African teenage girls are infected at a rate of five to six times greater than their male counter parts. The United Nations (UN) commission on the status of women expresses profound concern over the impact of HIV/AIDS on women and girls. It urges governments to take measures to empower them including economically to better protect themselves. The causes for the high HIV/AIDS infection rate among African teenage girls are multiple. Women are for biological reasons, more vulnerable than men to STIs and other opportunistic infections like HIV [2].

The situation is especially marked in girls whose genital tracts are still not fully mature. More important however, is sexual abuse and male sexual behaviour. Young girls often have sexual relationships with elder men who might coerce them to have sex in exchange for gifts and favours. Such unequal relationships tend to have consequences for women, in terms of their risk of infection. Earlier marriage for girls and unfaithful husbands, factors beyond girls' control, also highly contribute to infection rate.

It can be argued that women and girls do more work than men but are often neglected in most aspects of their lives. However, while this is true in most of the underdeveloped communities, it can be questionable in western perspective. A classic example could be drawn from an African context particularly from an ordinary family situation.

Early in the morning (author's experience), a wife usually wakes up to prepare the family for the day's work. She does this by preparing breakfast for both the husband and the children before they go to work and school respectively. She bathes the children and ensures that they put on clean clothes and this is also applicable to the husband. Furthermore, she takes care of herself and general cleanliness of the entire house including its surrounding.

If it is a subsistent farming home, she takes courage of joining the husband at the farm. As she knocks off from the farm, the husband goes straight back home while the wife fetches firewood ready to provide the husband with warm water for bathing. At the same time, she will also be preparing food for the entire family including the school children. By the time she goes to bed she is totally warn out. This is just a short version on how women work in certain communities.

The unfortunate part of this is that less attention is paid to their health, mental and psychological needs. Remember that when such things are happening, girls are there to learn what their mothers are doing. At times, these women are exploited not only physically but also sexually to such an extent that they are rendered powerless. Perhaps, this is one of the reasons that have contributed to the proliferation of HIV infection in women and young girls.

Reducing the stigma associated with HIV/AIDS: The stigma attached to HIV/AIDS patients prevents them from expressing most of their feelings and felt needs. They should be assisted to meet these needs such as expressing hostility, expressing and receiving love, secure recognition and sexual satisfaction.

It is said that if there is something which has to be respected in an individual is what he/she believes in. Therefore, freely allowing the persons living with AIDS to take charge of their lives is essential. In situations where HIV/AIDS projects are carried out, it is important that these people are incorporated right from the beginning of the intervention. Let them take active part in the project. Perhaps, it should be made clear that having HIV/AIDS is not a crime and does not reflect an ill character of an individual. The truth is that anyone can contract HIV infection.
Stigma prevents people living with HIV/AIDS to speak out their views openly. This is because many people look down upon them once they reveal their sero status. However, there are many factors that contribute to discrimination, stigmatization and denial (DSD). Local sexual beliefs are also determinants of HIV/AIDS related DSD [18].

Long held ideologies make it seem logical that while men seek many sexual partners (and receive social status of doing so), women should limit themselves to only one. To some extent, such practices are legitimatized by the traditional marriage bond, which denies women the opportunity to object when their husbands put them at risk. Ignorance, fear and lay beliefs are some of the determinants of HIV/ AIDS related DSD.

It is ideal to help people discover what they can do to make their situation in the short term. This calls for the change agent to focus on behavioural change although it cannot be achieved overnight. There is need to increase feelings of personal competence and to minimize exploitation of some members of the community simply because they are poor and have acquired HIV infection.

Respect for human rights/advocacy on HIV/AIDS and equal opportunities for all: The rights of people living with HIV/AIDS and their families are often violated. This is simply because they are not known. This violation hinders the response and increases the negative impact of the epidemic. Freedom from discrimination is the fundamental human right founded on the principles of natural justice that are universal and perpetual [7].

The key elements in the human right package according to the significant political and legal developments relating to HIV/AIDS are prevention, treatment, care and support. AIDS related human rights include advancement of rights to health, education, life, freedom from torture, cruel, inhuman or degrading treatment and freedom from slavery. Furthermore, the human rights advocates liberty, security, freedom from movement, information, freedom of expression, right to marry and privacy, equality between men and women and of course nondiscrimination.

Family planning: HIV/AIDS pandemic poses problems for family planning services at different levels. Some people fear that ready available and widespread use of contraception may encourage casual sexual relationships, and perhaps concurrent relationships, which would help the pandemic to spread. At the same time, the infertility is a major problem in parts of Africa and fear of infertility may discourage contraceptive use.

Worries about the return to fertility after using hormonal methods and even barrier methods may be compounded by lack of knowledge and confidence in the ability of condoms to protect against the disease. Studies in sub-Sahara Africa have shown that current use of condoms among women of reproductive age exceeds $1 \%$ only in Botswana, Ghana, Malawi, Zambia and Zimbabwe. Men tend to report higher usage (Over 1\% in Burkina Faso, Cameroon, and Senegal and over 5\% in Ghana, Kenya, Malawi and Tanzania). Yet huge numbers of them are at risk of HIV/AIDS in those countries, as elsewhere and condom use is likely to greatly reduce the risk [19].

Condoms can be used for dual protection (prevention from unwanted pregnancies and sexually transmitted infections including HIV infection). Perhaps this is what ought to be encouraged. On the other hand, if couples are aware of their HIV sero status, they will need to decide whether to have children or not. 
It should be noted that prevention and treatment can no longer be seen as unrelated strategies. None of them can occur in the isolation of each other. Therefore, a cultural element of a comprehensive HIV/ AIDS care strategies is the whole sole integration of prevention, treatment planning and intervention.

\section{Care Strategies}

\section{Provision of food to the needy}

Food aid plays a pivotal role in responding to HIV/AIDS. The first thing poor families affected by HIV/AIDS ask for is not cash or drugs, it is food. This is particularly common in poverty stricken areas. Food must be one of the weapons in the arsenal against this disease [20]. HIV/AIDS pandemic brings hunger to many societies particularly in Africa. This triggers the premature death of thousands of productive people.

Women and children across Southern Africa are severely affected as well as wrecking more millions, which will undoubtedly provoke future famines. Seven million farmers have lost their lives to AIDS in Africa and that is having a dramatic impact on food production [20]. World Food Programme (WFP) and UNAIDS are calling for a radical and urgent approach to address the fatal links between the diseases, chronic food shortages and malnutrition.

AIDS affected households are often hungry, farmers are too weak to plant, and families do not have the capacity to produce or purchase food. This situation forces people to adopt survival strategies that might endanger their lives. Some migrate often to slums where they lack access to education and health services. Women and children are found to barter sex for food, jobs and other basic essentials. Furthermore, children leave school to find work or forage for food.

\section{Home and community care}

From the time immemorial until the turn of the century, a family has often been seen as a more basic unit of any given society. It fulfills a lot of responsibilities such as nurturing and protecting its members. It is from the family where communities and the entire society emanate. Therefore, man as a social being has a strong affinity for the family. He/she needs the family in totality. The needs increase when his/her health is dilapidated with a more consuming disease like AIDS.

Elsewhere home and community care for AIDS patients has been observed as more effective than hospital care. Higher rates of pain treatment and lower likelihood of dying in a hospital were noted among the beneficiaries enrolled in a state wide HIV/AIDS specific home and community based Medicaid Waiver Programme. Furthermore, it was found that an access to home care services and case management mechanisms are effective means of facilitating palliative care. This increases the use of pain medication and reduces the likelihood of dying in a hospital [21].

In the event of looking after AIDS patients at home, there are several logistics that come into play. In most cases these logistics are not there. This poses a burden not only on the affected family, but also on the entire health care system. It was found that knowledge is vital in caring for these patients at home. In places where knowledge was low, people preferred taking AIDS patients for care at hospital level to caring for them at home level. They did this with every trivial complaint. This affected the productivity of these people and the health facilities too [22].
However, care for the AIDS patients outside the hospital is affected by many factors. The factors include poverty, divorce, ignorance and perhaps cultural beliefs. It is as a result of these that many HIV/AIDS patients quickly progress to AIDS and consequently culminate into death. This is particularly common in sub-Sahara Africa where the majority live below poverty line. People with HIV can live positively by gaining morale, rather than giving up. They can choose to eat good foods and not to smoke or drink alcohol. They can get immediate care for every infection.

\section{Availability and accessible voluntary counseling and testing (VCT) services}

It is important to break the silence in HIV/AIDS. Studies in Ghana showed that the secrecy affected the women's access to treatment, financial and emotional support from families. The secrecy surrounding breaking the news of HIV infection is one manifestation of AIDS stigma in many societies in Africa. Therefore, encouraging the disclosure within a trusting and supportive environment may be one strategy to diffuse AIDS stigma [23].

It is important that people should know about their HIV sero status because the advantages are multiple. For example, if one knows his/ her HIV status, he/she will be able to plan the family, make informed choices and prevent further spread of HIV infection. Furthermore, one can access the treatment for the opportunistic infections or the antiretroviral drugs. Consequently, this may have an impact on the quality of life.

Therefore, decentralization of VCT centers and civic education can possibly yield maximum benefit to many communities in AIDS epidemic areas and Malawi is no exception. In many developed countries studies have shown that counselors report that their work is stressful. Similar studies have also been done in Africa where counselors face the added difficulty that HIV affects them as well as their professional life. Their personal experiences and feelings may affect the effectiveness of their counseling. In the absence of effective cure for AIDS, HIV counseling and testing may be important in reducing the further spread of HIV infection.

\section{Prevention and treatment of AIDS and Tb including opportunistic infections}

The stigma about the association of Tb and HIV still exist in many communities in HIV affected areas. HIV and tuberculosis infections have many things in common. The two often coexist or sometimes not. The fact is that the presence of HIV infection in an individual usually predisposes him to tuberculosis and not vice versa. This is because HIV infection impairs body immunity which makes the body susceptible to many opportunistic infections including tuberculosis. This is why tuberculosis is more common in HIV endemic areas like sub-Saharan countries.

The difference is that $\mathrm{Tb}$ is curable whereas HIV is not. This was the analogy that surfaced in a study that was done in Tanzania. In that study it was found that may Tb patients believed that they had HIV/AIDS and therefore were going to die [24]. This had an effect on their compliance to treatment. They did not see the importance of completing the $\mathrm{Tb}$ treatment. This is an area that gives an allowance for creating community awareness of both $\mathrm{Tb}$ and HIV infections.

Besides Tb, AIDS patients suffer from many infections. Treatment of these infections including the use of antiretroviral drugs can improve their quality of life. The question is how many people in Africa would 
access these drugs? Perhaps this is an area worth looking at by different donors. It is impressive that in developed countries, HIV infected persons live longer (about 10 or more years). This is contrary to the developing countries where the majority of persons infected with HIV live below 10 years.

AIDS is an expensive disease that requires a considerable amount of money from the health system. A recent study estimated that the total costs for treating people with HIV disease in the United States in 1996 were between $\$ 6.7$ and $\$ 7.8$ billion with an average annual cost of treating each person estimated at between $\$ 20,000$ and $\$ 24,700$ [25]. This could amount to as much as half of the public health care systems to provide adequate care for AIDS patients and still try to meet all the other health needs of the public.

The situation is pathetic in the developing countries in that, if a lot of money is spent on HIV/AIDS care by developed nation like US, what more with the poor countries?. This is one explanation why majority of people in developing countries die in large numbers due to HIV as well as other diseases. The demand on the services caused by AIDS can also be illustrated by looking at the hospital beds. To those that seek care in the hospital the average stay is relatively longer than other diseases. As the prevalence rate grows so will the hospital beds requirements.

\section{Palliative care}

Palliative care is defined as patient, family centered care that optimizes quality of life by active anticipation, prevention and treatment of suffering. This care emphasizes use of an interdisciplinary team approach throughout the continuum of illness, planning critical importance on the building of respect and trusting relationships. Palliative care as complementary care should be provided throughout the course of HIV/AIDS progression, not just when a patient nears the end of life [26].

In Africa, where there has been traditionally a fairly strong bond through the extended family, the family has been and is still the greatest source of care for the sick people. AIDS now challenges the support to the family strength. Unless determined effort is made to restore the valuable condition, persons living with AIDS (PLWA) in Africa and other developing countries, will experience even greater difficulties than they do at present.

\section{Social, spiritual, psychological and peer support}

The importance of holistic approach in managing HIV/AIDS patients cannot be overemphasized. Integration of all dimensions that affect man has been seen as having the soothing effect not only to the persons living with AIDS but also to the entire family and the community. Psychological discomfort and psychiatric illnesses are commonly found among the late-stage AIDS patients [27].

Levels of psychological distress are further related to interpersonal problems with family members and both AIDS patients and their family members should benefit from psychological intervention in managing psychological burden brought about by HIV illness. Changing the attitudes towards holistic care of the sick is a necessity in comprehending the magnitude of AIDS, even after the deliberate efforts have been made. This indicates that the responsibility for caring for AIDS patients lies on every individual worldwide. In other words, what is required is the practical aspect of holistic approach as it is commonly said that the 'unit is as important as the whole'.

It has been observed that HIV/AIDS patients need most of the following; love, respect, health care, protein rich foods, shelter, material support such as clothing just like what any other person may need. When these needs are catered for they tend to live longer and make their end life meaningful. In terms of fear for the future counseling and frequent visits are ideal measures to alleviate these problems. This becomes more practical and acceptable if the family members take up the responsibilities. As a result of these, hope for the future even death becomes acceptable to them.

\section{Empowerment of people living with HIV/AIDS}

It is important that opportunities are created for persons living with AIDS to share their common experiences with others. These experiences include hopes, fears, rebuilding dignity, a sense of selfworth and friendship. Economic improvement is among the ways of empowering the persons living with AIDS. Many Non-Governmental organizations (NGOs) targeting HIV/AIDS activities have come up with different ways of empowering the persons living with AIDS.

Greater involvement of persons living with AIDS helps them to build up skills and confidence among HIV positive people through advocacy and treatment of opportunistic infections including $\mathrm{Tb}$. It is encouraging to see how much these people can do if given the technical support they need. Among these people peer educators can be trained to reach each other and this is another way of preventing HIV transmission.

People living with AIDS are often stigmatized and in some cases ostracized by their families and communities. Christian Aid partner organizations provide emotional support and counseling and try to improve their self-respect and esteem by giving them the means to earn a living with HIV/AIDS in many countries to help challenge the stigmas and denial often associated with HIV/AIDS [28].

AIDS prevention activities should be targeted to vulnerable groups such as women, young, prisoners and the underserved communities. All these people need information about responsible sexual behaviour and what they can do to improve their situation. It is commonly said that 'giving fish to somebody is not good enough but teaching him/ her how to catch fish is often the best'. This means that a lot of NGOs are disempowering their beneficiaries and as a result of this they create what is known as "dependency syndrome".

\section{Gender Issues in HIV/AIDS}

Gender is a term that is usually used to describe various characteristics assigned to women and men by a given society. The term sex refers to the biological characteristics of women and men. Whereas, gender roles reflect the behaviours and relationships that societies believe are appropriate for an individual based on his or her sex [29]. This often increases the risk of HIV/AIDS for both women and men. Gender can be explored in three different main ways namely sexual knowledge, sexual passivity and aggregation.

Women are of Africa's hidden growth reserves, providing most of the region's labour, but their productivity is hampered by wide spread inequality in education, power and access. This gender equality can be potent force for accelerating poverty reduction [30]. Gender equalities render women and girls more vulnerable in the area of sexual and reproductive health, thus increasing their vulnerability to HIV infection and disproportionate suffering from the consequences of the epidemic.

For this reason, aid agencies need to adopt long-term, timely, coherent and integrated AIDS prevention policy that includes public information and life based education programmes tailored to the needs of women and girls. Studies in Africa highlight that the 
majority of young women cannot protect themselves against AIDS because they have to rely on their male partners who may decide whether or not to use a condom. On this background, the call for empowerment of women and girls has been pronounced louder over the last years [29].

Prescribed gender roles result in asymmetric power relations between men and women and among groups of men and groups of women. These gender based inequalities are interlinked with other modifiers such as class, race, ethnicity, positions, geographical location and physical ability. Predominantly, gender power relations have left a legacy whereby women are more likely to be disadvantaged relative to men, have less access to resources, benefits to information and decision making and to have fewer rights both with the household and in the public sphere. Thus far, then, these concerns and the struggle for gender equality have been narrowly perceived to be a women's issue and gender programmes designed with a whole focus on women [31].

\section{Men and sexuality}

Matters of sexuality in African context have always been sidelined with confidentiality, privacy and sensitivity. It is seen as a taboo for parents to discuss sexual issues with their children and to themselves. Culture in most African societies, gives little room for serious talks between men about their own sexual experiences. Culture is however, dynamic, hence subject to change. Furthermore, culture is neither superior nor inferior but it is necessary to examine it carefully before its application is made.

Many surveys are now targeting men. The notion is to enable them to talk openly about sex among themselves and their spouses as well. It can be argued that often men take charge of sexual issues in the majority of families in Africa. More men practice extra marital sex than women. This puts a disadvantage over their spouses, for instance the wife might suggest condom use to her husband and the suggestion may work depending on the mood of the husband.

However, the suggestion that materializes most of the time is the one that comes from the man. In my own practice (author's experience) on Male Motivation on Family Planning, men were motivated to take initiative to reach their fellow men to use condoms for dual protection (use of condom as a contraceptive method and for STI/HIV prevention). It was found out that more men were motivated to use condoms than before. If women were to carry out the same task, they would have been probably associated with extra marital sexual practices.

The approach so far is working out positively but it needs replication so that the majority of men can be reached and take a responsible action on this. Men in diverse settings such as the homosexuals, bisexuals and all those involved in high risk behaviours should be targeted [32]. If men are not open in matters pertaining sexuality, there is often poor communication about sexual issues with their spouses. This predisposes them to sexually transmitted infections (STI) including HIV/AIDS and unwanted pregnancies.

Men like women, are affected by gender power structures that are interwoven with other hierarchical structures such as those based on race and class. Yet men regardless of their positioning in other hierarchical structures generally have a strategic common interest in defending and not challenging their general privilege. Men tend not to think of themselves as gendered beings, and this is one reason why policy makers and development practitioners, both men and women often misunderstand or discuss gender as a women's issue [31].
It should also be noted that men in certain occasions are battered by women. Therefore, the question of power struggle is equally the concern of both men and women. The classical example is that of domestic violence which is often underreported because of its sensitivity and humiliation. However, not much has been documented on issues regarding wives battering their husbands.

Domestic violence involves the violation of rights and human integrity, a display of power and subjection by one individual to another, in domestic setting of intimate relations or private sphere. In this sense, violation between siblings, elderly abuse, husband and wife beating, and child abuse are forms of domestic violence [33].

\section{Women and sexuality}

HIV infected women die faster of AIDS than men because of gender but not sex. Medically, it has not been explained why this is the case. However, other studies suggest that women wait longer than men before they seek treatment or they are treated differently. Providing adequate care to women can enable them respond even better to antiretroviral treatment and do not progress faster than men to AIDS [34].

Empowerment of women is seen as analogy for combating HIV/ AIDS. Studies have shown that women and young girls in certain societies particularly in Africa are not capable of making effective and informed decisions freely. This is applicable to girls who usually fall into risky behaviour because of material gains and of course money.

A feeling that one knows where he stands with other people, membership in definitive group and acceptance of moral order that provides rules for living and defines what is right or wrong. Opportunity to express spontaneity, creativity and to make choices should as well be equally cherished by all people regardless of sex or status including women. The situation should even be intensified when these women are infected with HIV/AIDS. It is sad that in many communities in Africa, women and children experience the catastrophic consequences of HIV/AIDS and often are marginalized.

Women (author's experience) in most communities in Africa including Malawi often get divorced as a result of being HIV positive. While this observation can be argued that the opposite is equally true, but the majority who are blamed and often held responsible for bringing HIV/AIDS in the home are women. To elaborate more on this, the author shares his experiences on managing a home and community care for the HIV/AIDS patients' project in Malawi. It was observed that $75 \%$ of female patients who were being visited regularly were divorced as opposed to $50 \%$ of male HIV/AIDS patients who were also divorced.

The female HIV/AIDS patients were being looked after by their children and of course their elderly mothers. A very strong statement made by a wife who was taking care of her terminally ill husband had the sentiments of love and care during difficult times. She said "I will continue looking after my terminally ill husband until he dies in my hands for this is what it means to be in marriage". Probing further into the conversation, it was reported that the sick man was doing very well financially but he never equally enjoyed his fortunes with his family. He spent more time with other women and often reported home late. It was when the illness got him when he surfaced in the home.

On the other hand, if the similar behaviors were to be portrayed by the wife, it is obvious that she could have hardly been accepted back into the home. No wonder one commented that women are our masters in the sense that we all came from them, they look after us until we grow up and we go back to them for marriage and nurse us till we die. 


\section{Donor Priorities and Policies}

Donors have a duty to perform but in essence, their duty and performance can be culturally accepted in the communities to be supported in question if they have been involved at every stage of development. This will help the communities to accept the programmes are implemented within their area. Contrary to this approach will lead to the collapse of the programmes.

The question of donor priorities and policies may be problematic to tackle. This is particularly when its application is to be utilized in a more diverse cultural settings like Malawi. Often people take it for granted that when one is in need, he does not have a choice of what to have or not. The notion may be partly true in that the poor frequently suffer from what is termed as 'inferiority complex'. This prevents them from calling a particular need by its right name.

Perhaps donors should always bear this in mind as many of them have different interests. At the same time communities have their own priorities too. In a poverty stricken environment, it is often not easy for people to make choices between what actually is their need and what it is not. They usually accept politely what the donor offers them.

Partly, this is due to being indoctrinated with customary values of being polite to handouts but could also be due to lack of civic education. It is recommended that in any given situation where an intervention project is being developed, an initial assessment must be done. The assessment, will determine the actual felt needs of the communities. This is very important if people at the grass root level have to benefit. Millions of dollars from donors are being wasted perhaps because this is commonly overlooked.

An integration of donor priorities/policies in the national policies to suit the existing local communities can largely support AIDS projects. On the other hand, this approach ensures the mechanism of sustainability for long-term projects. Furthermore, this will help one to distinguish the saying that 'it is our project' from 'it is theirs'. These key words matter a lot in that they form the basis at which a given project survives or dies an innocent natural death.

\section{Priorities}

It should be highlighted at this point in time that the following priorities and policies are generally applied by some of the aid agencies and governments both in developed and developing countries. The author's recommendation is that the readers should examine each of them carefully and see which ones can be applicable to their situations.

Prevention of HIV to control Tb and STI: There is clear evidence that there is a close association between HIV and Tb. Many HIV infected persons are at risk of developing Tb. It is estimated that one third to half of HIV infected people develop $\mathrm{Tb}$ and $\mathrm{Tb}$ has an adverse effect on HIV progression [7]. A lot of HIV infected people die from $\mathrm{Tb}$ and not necessarily to AIDS. It is important therefore to treat and control $\mathrm{Tb}$.

HIV/AIDS programmes to incorporate TB care and prevention: Measures applied to control and prevent HIV/AIDS can be helpful in dealing with $\mathrm{Tb}$. It is reported that 14,000 people become infected with HIV every day; the majority of them are in sub-Saharan Africa. One in three people with HIV/AIDS will die of TB [35]. Turning the tide will require strong political leadership and a dramatic increase in resources. HIV/AIDS is a global threat therefore, it needs a global responsibility.
Human capacity development for effective responses to HIV/ AIDS: Manpower is the back bone of any given institution if it is to survive and its integrity cannot be achieved overnight. It is the very same man power that has been adversely affected in most of the developing countries. The causes of this are multiple and of course poverty is the root cause of all many problems in these countries. Changing the clock as far as manpower is concerned, there is need to shorten the gap between the rich and the poor nations respectively. This is simply because developing manpower needs a lot of resources including money.

To prevent the spread of HIV/AIDS and reduce its impact, developing countries need to mobilize all levels of government and civil society. As a trusted development partner, UNDP advocates for placing HIV at the center of national planning and budgets; helps build national capacity to manage initiatives that include people and institutions not usually involved with public health and promotes decentralized responses that support community level action [31].

Working together to confront HIV/AIDS: The devastating social and economic consequences of HIV/AIDS could eventually be eradicated through a combination of treatment programs for opportunistic infections (OIs) and preventive activities. Achieving this goal requires adequate funding for procurement of drugs including antiretroviral drugs and improved networks of health care delivery, particularly in developing countries.

Consequences brought by HIV/AIDS worldwide are indications for the need of team work to combat this disease. In 2000, it infected more than 8,000 Hispanics in the United States. Although the daily heading about HIV/AIDS have gone away, the disease has not, particularly among the minority groups in the United States. This is even worse in most of the poor countries of the world [36].

The scenario calls for multicultural approach in a truest sense of the word. Program staff had to learn new skills that are traditionally taught in medical, nursing or social sciences and how to deal with media. They should be able to convince administrators and politicians to raise funds to support community health development. In this regard, there is need for aid agencies and governments to develop a culture of inclusion as they work towards a common goal.

It is somewhat perplexing when donor communities initiate new projects instead of supporting the already existing ones. While explanations may be given that there are several explanations to this, however, it should be born in mind that the practice brings along with it tremendous consequences. The negative effects of this practice include exodus of the work force from the existing projects to join such new projects with high pays. As a result of this, there is weakening of the networks and performance of the old established projects. Therefore, development becomes a farfetched phenomenon among the marginalized communities.

Arresting female morbidity and mortality due to AIDS: The untold harm and human suffering AIDS has caused to the world today cannot be overemphasized. People in many parts of the world have been affected in one way or the other. However, certain individuals within the communities are at a great risk. Women are affected more than men, particularly in sub-Saharan countries and it is these women who form over $60 \%$ of work force in these countries. It is therefore, of paramount importance to control the spread of HIV infection in women. 
AIDS is the leading cause of death in Africa and is the fourth leading cause of death worldwide. In 1992, it caused death among women in U.S. and this was accounted for by $14 \%$ [11]. In Africa and other developing countries the statistics are threatening. This is therefore, an indication that there is need to intensify preventive services among women and adolescents.

Prevention and mitigating AIDS in sub-Saharan Africa: AIDS in sub-Saharan region is killing a lot of people most of whom are in their prime age. The magnitude of the problem is seen by the escalating numbers of those that are annually being infected with HIV, dying to AIDS and the orphans. This draws the attention of both national and international bodies to put the resources together to arrest the situation as it is said that 'United we stand, divided we fall'.

Policies in HIV/AIDS prevention should be formulated in such a way that they benefit both men and women including the youth. Other high risk groups too should be targeted. The special requirements for HIV-prevention programmes by armed forces or insurgency groups in very poor countries that are in active conflict have not been well described [37].

Customary military programme components include: education on sexually transmitted diseases, condom distribution, and HIV testing.

Programmes for these armed forces must address: a command structure that may not prioritize this activity, severe resource and logistical constraints, weak health systems for treating sexually transmitted illness, beliefs in traditional medicines for symptoms of sexually transmitted illness, illiteracy that diminishes the utility of educational pamphlets, rape and sexual bartering by soldiers, battlefield transfusions, tattooing and the co-epidemic of tuberculosis.

An increase in research funding for the development of social and behavioural intervention aimed at protecting women and adolescents especially girls from infections: The search of new knowledge in an attempt to reduce HIV transmission cannot be overemphasized. Researches can yield good results if directed at sexually active adults in resource poor countries with high HIV incidence. As reflected more in this paper, women and girls need to be protected. Furthermore, these researches need to look into the roles played by social behaviours of people from different backgrounds.

The Corrections Demonstration Project (CDP) offers a model approach for addressing the poor health status of members of racial/ethnic minority groups by developing collaborations between corrections, public health departments, community-based organizations, and academia [38]. An outgrowth of this collaboration is the improved capacity to detect and treat disease, which is a necessary component of a comprehensive HIV risk reduction program.

\section{Policies}

\section{Governance Policy}

The policy focuses on the constitution, by laws, roles and responsibilities. These structures must be clearly stated for future references especially in times of problems. People living with AIDS need to be protected by Government policy. Barriers to returning to or remaining in the labor force are numerous and require a specific commitment to overcome.

Existing workplace, government policies, programs and labor market conditions impede labor force participation for people living with AIDS who have recovered from serious illness and are now able and willing to work [39]. It is important that once these policies are in place, civic education should be given to all the concerned parties.

\section{Framework policy}

This policy looks at an organization in terms of its mission statements and what it hopes to achieve. This means that the organization should formulate clear objectives and mechanisms put in place for long term sustainability.

\section{Operational policy}

Daily activities are looked into by this policy. The activities include personnel, finances and other activities as need be. Relations between senior officers and their subordinates are also dealt with by this policy.

\section{Corporate donations}

The basis of this policy is to maintain the networks especially when receiving donations in kind. It seeks to prevent conflicts among the donor agencies.

\section{Legal interventions}

The relevant rights of people living with AIDS are taken care of by this policy. It intends to ensure equal opportunities for all and also focuses on the care, treatment and support of these HIV infected people.

\section{HIV/AIDS Programme Implementers}

Internationally, there is a wide spectrum of organizations that deal with HIV/AIDS prevention and care activities. The organizations include World Health Organization (WHO), United Nations Development Programme (UNDP), and Joint United Nations Programme on HIV/AIDS (UNAIDS), United Nations Children Fund (UNICEF), World Food Programme (WFP) UNAIDS, NORAD, USAID, World Bank, World Vision International and Medicins Sans Frontiers among others.

The presence of these organizations worldwide is spread ranging from the regions, countries as well as districts. Among these organizations there are Government and Non-Governmental ones. However, there are also faith based organizations which fall within the Non-Governmental organizations. These faith based organizations work hand in hand with governments to help them achieve their objectives in different interventions.

In Malawi, the situation is in such a way that these different international and national organizations including the faith based and community based organizations work hand in hand with Malawi Government. Often problems arise when organizations with similar interests compete for the same resources or treat their members of staff differently. However, this is not a significant problem in Malawi as there is a mechanism for coordination among the NGOs.

The differences between NGOs are multiple and the detailed information about these differences is beyond the scope of this paper. However, some of the major differences include the stability of the economic basis and areas of concentration and locality. Some NGOs in Malawi serve the rural population whereas others serve the urban population. Consequently, other NGOs have a more stable economy than others.

There are four main agencies providing health services in Malawi. These are Ministry of Health and Population (MoHP)-60\%, Christian Hospitals Association of Malawi (CHAM)-37\%, Local 
Citation: Kasenga FH (2017) HIVIAIDS Prevention and Care Strategies: An Interdisciplinary Perspective. J Health Med Informat 8: 291. doi: 10.4172/2157-7420.1000291

Page 11 of 12

government-1\% and Private Organizations-2\%. The Government and the Non-governmental organizations (NGOs) deliver health care services in Malawi. Among the NGOs, there are healths facilities ran by Missionaries but subsidized by the Government and others are private owned as stated above. Health facilities ran by Missionaries has membership to an organization called Christian Hospitals Association of Malawi (CHAM).

CHAM coordinates all the health services that are carried out by these health facilities that are ran by the churches. Malawi Government funds these facilities through CHAM. Therefore NGOs are important in effecting change world wide

\section{Conclusions}

HIV/AIDS management cannot be carried out in isolation. Therefore, multisectoral collaboration should be employed at all levels of development. This means that individuals, organizations and aid agencies should join hands to fight against this very important public health problem.

People living with AIDS should be treated with love, dignity and respect like those with any type of infection. This will help improve their quality of life and make life meaningful to themselves and to their families. The notion will facilitate openness and willingness to share their experiences with others and eventually reduce HIV transmission.

Poverty, ignorance and diseases are rampart in developing countries. Anybody committed to make a significant change in a truest sense of the word among the inhabitants of these countries should be flexible and willing to learn. Furthermore, communities should never be taken for granted since they have long been managing in the absence of external force.

\section{Acknowledgements}

It takes more than one person to come up with a document of this nature. wish therefore, to express my heartfelt thanks and appreciation to all the people whose efforts have made this piece of work a reality.

Special thanks go to my donor, Fredskorpset-Norway for funding the entire Programme without which this piece of work would have been a non-starter. I would also like to thank Mrs. Elsa Døhlie, Øyvind Eggen, May-Britt Krogsvold, Sidse Roalkvam and Elizabeth Nygaard, all of International Department, Diakonhjemmet College and all the members of staff at Diakonhjemmet for their valuable and practical assistance during my entire period of my work.

Also I wish to thank most especially my South partner-CHAM Secretariat for facilitating my legibility to participate in this Fredskorpset Exchange Programme. To name but a few; Mrs. R. Mwandira and Miss D. Mhango-Executive Director and Nursing/Training Officer respectively for $\mathrm{CHAM}$ and others at $\mathrm{CHAM}$ too numerous to mention. Special thanks go to Management and staff of Malamulo Seventh Day Adventist Hospital for supporting and enabling me to participate in this programme.

I also wish to thank all my fellow Frediskorpset participants for their moral support and encouragement during the entire period of this exercise. Last but not least, I thank Grace Kasenga for her unfailing confidence and encouragement. It would also be unfair never to acknowledge the patience and long suffering of my beloved children namely Happy, Upendo and Sungani.

Please note that the above listed text books and publications on HIVIAIDS have influenced my preparation and write up of my prescribed assignment. However, not all of them have been quoted and put on the reference list!

\section{DEDICATION}

This piece of work is dedicated to all those who lost their lives to HIVIAIDS and those who are striving to fight against this deadly disease.

\section{References}

1. Morrison C, Richardson B, Rugpao S, Mugwera R, Mmiro F, et al. (2003) Clinical Trial: Hormonal Birth Control and the Risk of Acquiring HIV.

2. UNAIDS (2001) Women empowerment necessary to fight AIDS
3. UNAIDS/WHO (2002) Epidemiological fact sheet on HIVIAIDS and sexually transmitted infections in Malawi.

4. Hutchinson (1999) Multimedia Encyclopedia CD-ROM, Helicon

5. Kanjaye H (1999) International Press Service.

6. UNAIDS/WHO (2000) Epidemiological fact sheet on HIVIAIDS and sexually transmitted infections in Malawi.

7. UNAIDS (2002) Women empowerment necessary to fight AIDS

8. Obiechina NJ, Diwe K, llepeze OC (2002) Knowledge, awareness and perception of sexually transmitted infections (STIs) among Nigerian adolescent girls. J Obst Gyn 3: 302-305.

9. AIDS Foundation (2001) HIV Vaccines and Microbicides: Speed the Development of Effective and Accessible HIV Vaccine (s) and Microbicide (s).

10. Kelvin K, Warren P, Graem L (2001) Reconceptulizing behaviour change in HIVIAIDS.

11. CDC (1998) The Body: An AIDS and HIV information resource.

12. PSI, UNAIDS (1997) Social Marketing: An effective tool in the Global Response to HIVIAIDS. UNAIDS1: 1-20.

13. Hellinger FJ, Fleishman JA (2000) Estimating the National Cost of Treating People with HIV disease: Patient, payer and provider data. J Acquir Immune Defic Syndr 24: 182-188.

14. Mitike G (2002) HIV/AIDS Risk Awareness 'Very low' Survey Finds, UN Integrated Regional Information Networks.

15. FHI (2002) Reducing HIV in Injection Drug Users (IDU).

16. Dai ZY, Gu XY, Wu J (2002) Medical legal identification of post-transfusion HIV/ AIDS. Fa Yi Xue Za Zhi. 18: 189-191.

17. UNICEF (2002) Mother to Child Transmission of HIV, The Mekong Partnership and Beyond, UNICEF and HIVIAIDS in East Asia and the Pacific.

18. Sophia M, Monico E, Otolok T, Augustus N (2001) Uganda: HIV and AIDS related Discrimination Stigmatization and denial. AIDS 1: 1-34.

19. Khanna J (1998) Family Planning and HIVIAIDS, Contraceptive Research and Development (CONRAD): Major advances during 1998-1999, JHPIEGO Corporation.

20. Morris JT (2003) World Food Programme (WFP), and UNAIDS join forces against HIVIAIDS.

21. Sambamoorthi U, Walkup J, Mc Spirit E, Warner L, Castle N, et al. (2000) Racial differences in end-off life care for patients with AIDS. AIDS Public Policy J 15: 136-148.

22. Zimba EW, Mc Inerney PA (2001) The knowledge and practice of primary care givers regarding home based care of HIVIAIDS children in Blantyre (Malawi) Curationis 24: 83-91

23. Mill JE (2003) Shrouded in Secrecy: breaking the news of HIV infection to Ghananian women. J Transcult Nurs 14: 6-16.

24. Kasenga FH (2000) Perceptions towards TB treatment in TB patients who think are HIV infected versus.

25. Fred JH, John AF (2000) Estimating the national cost of treating people with HIV disease: Patient, payer and provider data. J Acquir Immune Defic Syndr 24: $182-188$.

26. Duke T (2003) A Clinical Guide to Supportive and Palliative Care for HIVIAIDS Health Hum Sci Iss 1: 2-9.

27. Pozzi P (2001) AIDS, Psychiatric \& Psychological Distress and Family Intervention. Institute of Psychiatry and Psychology, Catholic University of the Sacred Heart, Rome, Italy.

28. Christian Aid (2002) Information from Christian Aid: HIVIAIDS.

29. UNAIDS/WHO (2001) Epidemiological fact sheet on HIV/AIDS and sexually transmitted infections in Malawi. WHO 1: 1-16.

30. World Bank (2000) Can Africa claim the 21st century? W B 1: 1-292.

31. Allan G, Michael k, James L (2000) Men, Masculinities, and development? Broadening our work towards gender equality. UNDP 1: 1-28. 
Citation: Kasenga FH (2017) HIVIAIDS Prevention and Care Strategies: An Interdisciplinary Perspective. J Health Med Informat 8: 291. doi: 10.4172/2157-7420.1000291

32. Colby DJ (2003) HIV knowledge and risk factors among men who have sex with men in Ho Chi Minth City, Vietnam. J Acquir Immune Defic Syndr 32: 80-85

33. Hasanbegovic (1999) The feminine is political, Domestic Violence and its similarities with torture, Paper presented at the 7th Women World's Interdisciplinary Conference, University of Tromso.

34. Kremer H, Sonnenberg-Schwan U (2003) Women living with HIV, Does sex and gender matter? A current literature review. Eur J Med Res 8: 8-16.

35. Bill \& Melinda G (2002) The fight against AIDS and Tuberculosis. Glob health 25: $1-2$.
36. Anderson M (2002) Mother, Daughter Team Encourages HIVIAIDS Awareness in minorities. Amer Red cros 2: 89-95.

37. Miles SH (2003) HIV in insurgency forces in sub-Saharan Africa - a persona view of policies. Int J STD AIDS 14: 174-188.

38. Arriola KR, Braithwaite RL, Kennedy S, Hammett T, Tinsley M, et al. (2001) A collaborative effort to enhance HIV/STI screening in five county jails. Public Health Rep 116: 520-529.

39. Maticka-Tyndale E, Adam BD, Cohen JJ (2002) To work or not to work: combination therapies and HIV. Qual Health Res 12: 1353-1372. 